\title{
Aristolochia bracteolata Enhances Wound Healing in vitro through Anti-inflammatory and Proliferative Effect on Human Dermal Fibroblasts and Keratinocytes
}

\author{
Dinesh Murugan Girija', Mangathayaru Kalachaveedu²*, Rajasekaran Subbarayan ${ }^{3}$, Preethi Jenifer ${ }^{2}$, \\ Suresh Ranga Rao ${ }^{4}$
}

\section{Dinesh Murugan Girija', Mangathayaru \\ Kalachaveedu2*, Rajasekaran Subbarayan ${ }^{3}$, Preethi Jenifer ${ }^{2}$, Suresh Ranga Rao ${ }^{4}$}

\section{${ }^{1}$ Centre for Indian Systems of Medicine Quality Assurance and Standardization Sri Ramachandra University, Chennai, Tamil Nadu, INDIA. \\ 2Faculty of Pharmacy, Sri Ramachandra University, Chennai, Tamil Nadu, INDIA. ${ }^{3}$ Centre for Regenerative Medicine and Stem Cell Research, Sri Ramachandra University, Chennai, Tamil Nadu, INDIA. ${ }^{4}$ Department of Periodontology, Sri Ramachandra University, Chennai, Tamil Nadu, INDIA.}

Correspondence

Dr. Mangathayaru Kalachaveedu

Department of Pharmacognosy, Faculty of Pharmacy, Sri Ramachandra University, Porur, Chennai-116, Tamil Nadu, INDIA.

Phone no: 91-91-9940014632

E-mail: kvmanga@yahoo.com

\section{History}

- Submission Date: 26-09-2017.

- Review completed: 08-10-2017;

- Accepted Date: 02-11-2017

DOI : 10.5530/pj.2017.6s.169

Article Available online http://www.phcogj.com/v9/i6s

\section{Copyright}

(c) 2017 Phcog.Net. This is an openaccess article distributed under the terms of the Creative Commons Attribution 4.0 International license.

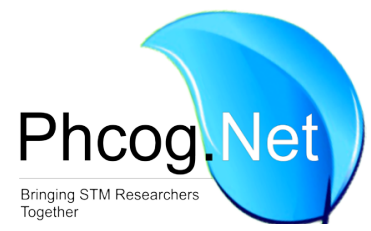

\begin{abstract}
Objective: In the present study, we examined the effect of Aristolochia bracteolata extract on Human dermal fibroblast (HDF) and Human keratinocyte cell line (HaCaT) proliferation and migration during in vitro wound healing and its underlying mechanism. Method: A. bracteolata was collected and extracted using methanol. Cytotoxiciy effect of plant extract was determined by MTT assay in HDF and HaCaT. In vitro Scratch assay determined the effect of plant extracts on migration of cells and its underlying mechanism was determined by RT-PCR analysis. Result: The plant extract of $A$. bracteolata selectively inhibited proliferation of both the cells at higher concentration ( $>100 \mu \mathrm{g} / \mathrm{mL}$ ) and at lower concentrations $(<25 \mu \mathrm{g} / \mathrm{mL})$, it exhibited linear and dose-dependent cell proliferation. $I C_{50}$ value was $87.60 \pm 1.67 \mu \mathrm{g} / \mathrm{mL}$ for HDF and $85.50 \pm 1.65 \mu \mathrm{g} / \mathrm{mL}$ after $24 \mathrm{~h}$ treatment. In vitro scratch wound healing studies showed wound closure of $50.38 \% \pm 1.39$ and $69.81 \% \pm 1.89$ at a concentration of $25 \mu \mathrm{g} / \mathrm{mL}$ after $24 \mathrm{~h}$ and $48 \mathrm{~h}$, respectively. The extract was tested for anti-inflammatory activity by determination of inhibitory activity on lipopolysaccharide (LPS) induced nitric oxide (NO) production in RAW 264.7 cell lines. We found that $A$. bracteolata has a strong inhibitory effect on the production of NO and tumor necrosis factor- $\alpha$ (TNF- $\alpha$ ). The plant extract of $A$. bracteolata inhibited inducible nitric oxide synthase (iNOS) gene expression by lipopolysaccharide (LPS). To explore the mechanism responsible for the inhibition of iNOS, gene expression was analyzed by RealTime PCR. A. bracteolata showed a decrease in the expression of pro-inflammatory cytokine mRNA in a concentration-dependent manner. Treatment with the plant extract resulted in enhanced expression of Collagen $1 \mathrm{a}$ (I) and Collagen IV in HDFs by regulating the mRNA levels of extracellular matrix (ECM) proteins and Matrix metalloproteinase-2. Conclusion: Thus, the present investigation scientifically validates the use of $A$. bracteolata in wound healing. Key words: A. bracteolata, Scratch assay, Wound Healing, Fibroblast, Keratinocytes, RAW 264.7
\end{abstract}

\section{INTRODUCTION}

Wound healing is a multifaceted biological process characterized by different overlapping phases namely, inflammation, the formation of granulation tissue, re-epithelialization and tissue reorganization. ${ }^{1}$ These overlapping phases, accomplished primarily by dermal fibroblasts and keratinocytes and as well-orchestrated by bioactive molecules as well as growth factors, cytokines, and their receptors, and matrix molecules. Key to this repair process is the proliferation, migration, and functioning of fibroblasts and keratinocytes. ${ }^{2}$ Since ancient times, a large number of plants/plant extracts/decoctions or pastes are regularly used by tribals and folklore tradition in India for the treatment of cuts, wounds, and burns to accelerate the wound healing process. ${ }^{3}$ Plant products are the potential agents for wound healing and are largely preferred because of their widespread availability, lack of side effects and effectiveness as crude preparations. ${ }^{4}$ Often their use is merely based on tradition, without any scientific evidence of efficacy and little knowledge about putative active compounds or their mode of actions. Efforts are being made all over the world to discover agents that can promote healing by reducing the cost of hospitalization and save patients from amputation and other severe complications.

A. bracteolata is commonly called "worm killer" in English due to its supposed anthelmintic activity and trypanocidal effect. A. bracteolata is a common medicinal plant that belongs to the family Aristolochiaceae. Traditionally, A. bracteolata has been reported to be used for fever, inflammatory diseases, and insect bites. The whole plant was used as anthelmintic, purgative, antipyretic, anti-inflammatory agents. The plant contains Aristolochic acid which

Cite this article: Girija DM, Kalachaveedu M, Subbarayan R, Jenifer P, Rao SR. Aristolochia bracteolata Enhances Wound Healing in vitro through Anti-inflammatory and Proliferative Effect on Human Dermal Fibroblasts and Keratinocytes. Pharmacog J. 2017;9(6)Suppl:s129-s36. 
has many medicinal properties in various disease conditions. It is used in traditional medicine in the treatment of cancer, as a gastric stimulant lung inflammation, dysentery, and snakebites. ${ }^{5}$ It is also employed in the treatment of tumors, malaria, and fever. ${ }^{6}$ A. bracteolata showed a distinctly positive effect on wound healing with a significant increase in the level of powerful antioxidant enzymes. ${ }^{7}$ It also possesses a potent anti-allergic activity.

As wound healing is a complex biological process, several in vitro and in vivo assays are available for analyzing the potent wound healing drugs. In vitro tests are now widely employed in pharmacological research because of ethical reasons and of their utility in bioactiveguided fractionation and determination of active compounds. ${ }^{8}$ Among these, the scratch wound assay using fibroblasts and keratinocytes has been proven as a valuable and inexpensive tool to obtain first insights into how plant preparations or their isolated compounds can positively influence the formation of new tissue. ${ }^{9}$ Given the overlapping phases of the wound healing process, a plant-based remedy should affect at least two different processes before it can be said to have some scientific support for wound healing use.

This study is, therefore, aimed to evaluate the wound healing effect of methanolic extract of $A$. bracteolata by using different in vitro cell culture systems. In this study, we used human dermal fibroblasts (HDF), human keratinocyte cell lines (HaCaT) and murine macrophage cell lines (RAW 264.7) to examine the effect of A. bracteolata on the patterns of cellular proliferation, migration, anti-inflammation and associated mechanism of action using RT-PCR analysis for the scientific support.

\section{MATERIALS AND METHODS}

\section{Chemicals and reagents}

The chemicals $\alpha, \alpha$-Diphenyl- $\beta$-picrylhydrazyl (DPPH), ascorbic acid, 3-(4,5-dimethyl-2-thiazolyl)-2,5-diphenyl-2H-tetrazolium bromide (MTT) were obtained from Sigma (St. Louis, MO). Dulbecco's Modified Eagles medium (DMEM), fetal bovine serum (FBS), penicillin-streptomycin were obtained from Gibco BRL (Grand Island, NY, USA). 3[H] Thymidine was purchased from Perkin Elmer, USA. Thin layer chromatography (TLC) was performed by using a commercially available flexible TLC silica gel (silica gel 60, F254) plates and compounds were visualized using short wave ultraviolet light. Chemicals and reagents employed in the present studies were of analytical grade, purchased from Sigma (St.Louis, MO).

\section{Collection of plants}

Aerial parts of Aristolochia bracteolata was collected from Pechipparai Village in Kanyakumari District of Tamil Nadu, India (Lat: 8.369892, Long: 77.223759). A certified Botanist authenticated them; a herbarium sample was deposited in the Centre for Indian Systems of Medicine Quality Assurance and Standardization, SRU Ref No. CRF -HRL/SRU121/2014).

\section{Plant extract preparation}

The leaves of $A$. bracteolata were air-dried in the shade and finely powdered. The leaf extract was prepared by keeping $100 \mathrm{~g}$ of leaf powder soaked in $250 \mathrm{~mL}$ of methanol for $72 \mathrm{~h}$. The plant extracts were filtered through Whatman filter paper no 1 and evaporated at $<40^{\circ} \mathrm{C}$. The process was repeated three times. The concentrated plant extract was dissolved in dimethylsulphoxide (DMSO) (Himedia, Mumbai) to get a stock solution of $5 \mathrm{mg} / \mathrm{mL}$. The sub-stock solution of $0.2 \mathrm{mg} / \mathrm{mL}$ was prepared by diluting $25 \mu \mathrm{L}$ of the stock solution into $975 \mu \mathrm{L}$ serum-free culture medium, DMEM (the percentage of DMSO in the experiment should not exceed $0.5)$. The stock and sub-stock solutions were stored at $4^{\circ} \mathrm{C}$.

\section{Free radical scavenging assay}

$\alpha, \alpha$-Diphenyl- $\beta$-picrylhydrazyl (DPPH) assay was used for determining free radical scavenging ability of various leaf extracts. ${ }^{10}$ This method is based on the reduction of DPPH to DPPH-H (non-radical form) in methanol in the presence of a hydrogen-donating antioxidant. Reduction of free radical results in color change which is measured spectrophotometrically. The reaction mixture $(3.0 \mathrm{~mL})$ consisted of $1.0 \mathrm{~mL}$ of DPPH in methanol $(0.3 \mathrm{mM}), 1.0 \mathrm{~mL}$ of extract and $1.0 \mathrm{~mL}$ of methanol. Reaction mixtures were incubated for $10 \mathrm{~min}$ in the dark before absorbance was measured at $517 \mathrm{~nm}$. Ascorbic acid was used as the standard.

\section{High-performance thin layer liquid chromatography (HPTLC) fingerprint}

HPTLC was carried out on $20 \times 10 \mathrm{~cm}$ aluminum plates coated with silica gel GF254 (Merck, Germany). Quercetin as standard and A. bracteolata extracts were applied to the plates with the bands of width $1.0 \mathrm{~cm}$ using a Camag Linomat V sample applicator equipped with a $100-\mu \mathrm{L}$ Hamilton syringe. Toluene: ethyl acetate at the ratio of 3:2 (M1) or hexane: ether at the ratio of 2:3 (M2) saturated in a Camag glass twin-trough chamber at room temperature was used as mobile phases. After development, the TLC plates were dried with a hair dryer and scanned under visible light, and UV at 254 and $366 \mathrm{~nm}$ with a Camag TLC Scanner with WINCAT software using the deuterium lamp. The relative fronts $(R f)$ of the samples were calculated using the following formulae:

Relative fronts $(R f)=D$ sample $(\mathrm{mm}) /$ Dmobile phase $(\mathrm{mm})$

Where D sample is the distance of the sample $(\mathrm{mm})$ and Dmobile phase is the distance of the mobile phase ( $\mathrm{mm})$.

\section{Cell line and culture conditions}

Human dermal fibroblasts cells (HDF) and human keratinocyte cell lines (HaCaT) and RAW 264.7 cells were purchased from National Centre for Cell Sciences (NCCS), Pune. Cells were cultured in DMEM supplemented with $10 \%$ fetal bovine serum (FBS), $4 \mathrm{mM} \mathrm{L-glutamine,} 1 \%$ penicillin/streptomycin under a fully humidified atmosphere containing $5 \% \mathrm{CO}_{2}$ at $37^{\circ} \mathrm{C}$. For experiments, cells were collected from subconfluent monolayers with trypsin/EDTA. Cell viability was determined using trypan blue dye exclusion staining. In all experiments, untreated cells were used as controls. All cell culture reagents and recombinant human epidermal growth factor (EGF) used as positive control in the migration assay were obtained from Sigma Aldrich, USA.

\section{Assessment of cell viability and altered morphology Assessment of cell viability}

Cell proliferation was determined by the 3-(4,5-dimethylthiazol-2-yl)2,5-diphenyltetrazolium bromide dye uptake method. ${ }^{11}$ Briefly, $\left(5 \times 10^{3}\right.$ cells/well) cells were seeded into 96-well plates after $24 \mathrm{~h}$ cells were treated with various concentration of A.bracteolata ranging from $(1-250 \mu \mathrm{g} / \mathrm{mL})$ or vehicle alone $(0.1 \% \mathrm{DMSO})$ in serum-free media. After incubation for indicated times, MTT $(5 \mathrm{mg} / \mathrm{mL})$ was added to the plate and cells were incubated for $4 \mathrm{~h}$ in the dark at $37^{\circ} \mathrm{C}$. The resulting MTT-products were dissolved in DMSO and determined by measuring the absorbance at $570 \mathrm{~nm}$ with ELISA reader.

\section{Thymidine incorporation assay}

$3[\mathrm{H}]$ Thymidine incorporation assay was performed as described by Moon et al., 2004. In brief, the cells were plated onto 12-well culture plates at $25 \times 10^{3}$ cells/well and incubated at $37^{\circ} \mathrm{C}$ in $5 \% \mathrm{CO}_{2}$ for $48 \mathrm{~h}$ in DMEM medium. Following incubation, plant extracts at $1-100 \mu \mathrm{g} / \mathrm{mL}$ concentration were added to the wells in triplicate, leaving three wells as a control before the addition of $3[\mathrm{H}]$ thymidine $(1 \mu \mathrm{ci} / \mathrm{mL})$ to all 
wells. After incubation for $48 \mathrm{~h}$, the cells were washed with PBS and then fixed with $10 \%$ ice-cold trichloroacetic acid to precipitate the DNA. The Radioactivity was measured in scintillation solution using liquid scintillation spectrometry (Perkin Elmer, USA). The concentration of the sample was then plotted against the percentage cell survival.

\section{In vitro wound healing assay}

$\mathrm{HDF}$ and $\mathrm{HaCaT}$ cells were grown in 6-well plates at a density of $3 \times 10^{6}$ cells per $\mathrm{mL}$. A small linear scratch was created in the confluent monolayer by gently scraping with sterile cell scrapper as per standard methods. ${ }^{12}$ Cells were extensively rinsed with medium to remove cellular debris before treating with different concentrations $(25,50,100,250$ $\mu \mathrm{g} / \mathrm{mL}$ ) of plant extracts in FBS deprived condition. Epidermal growth factor (EGF) was used as positive control distinctly to judge the rate of cell migration. $24 \mathrm{~h}$ later, images of the migrated cells were taken using a digital camera (Nikon, Ti Eclipse Tokyo, Japan), connected to the inverted microscope and analyzed by image analysis software (Image J, National Institutes of Health, Bethesda, MD, USA). The extent of wound healing was determined by the distance traversed by cells migrating into the denuded area. Representative data is cumulative of three independent experiments. Images of the wounded area were taken at a 10x magnification using a phase contrast microscope on day 0 ; then plates were incubated at $37^{\circ} \mathrm{C}$ with $5 \% \mathrm{CO}_{2}$ and photographs were taken on days 1 and 2. The images acquired from each sample were further analyzed quantitatively using computing software. By comparing the images from day 0 to 2, the distance of each scratch closure was determined, and the percentage migration rate was calculated according to.$^{13}$ In each well, two scratches were made (left and right) and per scratch, six points were considered. Average of left scratch and right scratch were taken separately. Percent migration was calculated for left scratch and then right scratch using.

The percentage of wound closure was calculated as follows:

(Area of original wound $\times$ Area of actual wound)/Area of original wound $\mathrm{X} 100 .^{14}$

\section{In vitro anti-inflammatory activity Measurement of NO production}

NO production was assayed by measuring the nitrite in the supernatants of cultured RAW 264.7 cells as described by Kang et al., 2008. Cells were seeded at $5 \times 10^{5} / \mathrm{mL}$ in 96 -well culture plates and cultured for $18 \mathrm{~h}$. The cells were stimulated with LPS ( $200 \mathrm{ng} / \mathrm{mL})$ and test agents for $24 \mathrm{~h}$, then briefly centrifuged. The supernatant was mixed with an equal amount of Griess reagent ( $1 \%$ sulfanilamide, $0.1 \%$ naphthyl ethylenediamine dihydrochloride, and $2.5 \%$ phosphoric acid) and incubated at room temperature for $5 \mathrm{~min}$. The concentrations of nitrite were measured at $570 \mathrm{~nm}$. Sodium nitrite $\left(\mathrm{NaNO}_{2}\right)$ was used to generate a standard curve.

\section{RNA extraction and reverse transcription-PCR analysis}

Approximately $6 \times 10^{6} \mathrm{HDF}$ cells were seeded in 6-well plates and incubated at $37^{\circ} \mathrm{C}$ for $48 \mathrm{~h}$. After the cells reached confluence, the scratch wound was induced as described in material and methods section. Cells were treated with an $\mathrm{IC}_{50}$ concentration of plant extracts for $48 \mathrm{~h}$. For inflammatory studies, RAW 264.7 cells were seeded and pre-treated with the indicated concentration of plant extracts and stimulated with LPS (200 ng/mL). Total RNA was isolated from cells in culture using Trizol Reagent (GibcoBRL) according to manufacturer's instruction. RNA concentrations and purity were measured with a spectrophotometer (Bio photometer plus, Eppendorf, USA). For reverse transcription (RT), $1 \mu \mathrm{g}$ of total RNA was used in a final volume of $10 \mu \mathrm{L}$ containing $250 \mathrm{pmol}$ of random hexamers, $1 \mu \mathrm{L}$ buffer, $25 \mathrm{mM}$ of dithiothreitol, $10 \mathrm{mM}$ of each dNTP, $100 \mathrm{U}$ of Super-script II reverse transcriptase enzyme and then transcribed into cDNA using the Verso cDNA Synthesis Kit (Roche, Mannheim, Germany). The reaction was carried out at $42^{\circ} \mathrm{C}$ for $45 \mathrm{~min}$, then at $92^{\circ} \mathrm{C}$ for $5 \mathrm{~min}$. PCR amplification was performed using $10 \mu \mathrm{L}$ of the RT reaction in a final volume of $50 \mu \mathrm{L}$, containing $1 \mathrm{x}$ PCR buffer (GibcoBRL), $0.2 \mathrm{mM}$ of each dNTP, 1.5mM MgCl2, 1.5U of Taq DNA polymerase (GibcoBRL,US), $1 \mu \mathrm{M}$ of primer forward (F) and $1 \mu \mathrm{M}$ of primer reverse (R). The PCR cycling profile was as follows: $94^{\circ} \mathrm{C}$ for $3 \mathrm{~min}$, then $30-36$ cycles of $94^{\circ} \mathrm{C}$ for $45 \mathrm{sec}, 56-65^{\circ} \mathrm{C}(\mathrm{Tm})$ for $30 \mathrm{sec}$, $72^{\circ} \mathrm{C}$ for $1 \mathrm{~min}$, and a final extension at $72^{\circ} \mathrm{C}$ for $10 \mathrm{~min}$ (Mastercycler gradient thermocycler, Eppendorf). PCR samples were amplified using specific primers, PCR conditions were optimized, and linear amplification range was determined for each primer by varying annealing temperature and cycle number. Products were separated on $2 \%$ agarose gels and visualized by using safe dye (Biolegend, USA). Primers for $\beta$-actin, GAPDH, MMP-1, MMP-2, collagen I \& III were used. The PCR amplification for all primers was performed for 45 cycles. The expression levels of genes of interest were normalized against the housekeeping gene GAPDH. Negative control reactions containing samples without cDNA were used.

\section{Statistical analysis}

For multiple group comparison of cell proliferation, cell migration, and NO production, the significance of the differences between the treatment groups and their respective control groups were tested by one-way ANOVA with Dunnett's post-experimental data. All experiments were performed three times, and the data are presented as the Mean \pm standard deviation (SE). P value of less than 0.05 was considered statistically significant. Monolayer wound healing assay data were analyzed by a twoway ANOVA with the independent factors experiment and treatment followed by Bonferroni post-hoc tests.

\section{RESULTS}

In the DPPH photometric analyses, the methanolic extract of $A$. bracteolata showed a similar antioxidant activity with that of ascorbic acid as standard at varying concentration tested $(5,10,25,50,125,250,500 \mu \mathrm{g} / \mathrm{mL})$. Figure 1 shows that extract reduced DPPH radicals significantly as compared to the control $(\mathrm{p}<0.05)$. As shown in Figure $1 \mathrm{EC}_{50}$ value of A. bracteolata was found to be $43.88 \mu \mathrm{g} / \mathrm{mL}$ compared with ascorbic acid which showed the $\mathrm{EC}_{50}$ value of $6.03 \mu \mathrm{g} / \mathrm{mL}$. There was a dose-dependent increase in the percentage antioxidant activity for all concentrations tested (Figure 1). A. bracteolata at a concentration of $1 \mu \mathrm{g} / \mathrm{mL}$ showed

\section{Antioxidant activity}

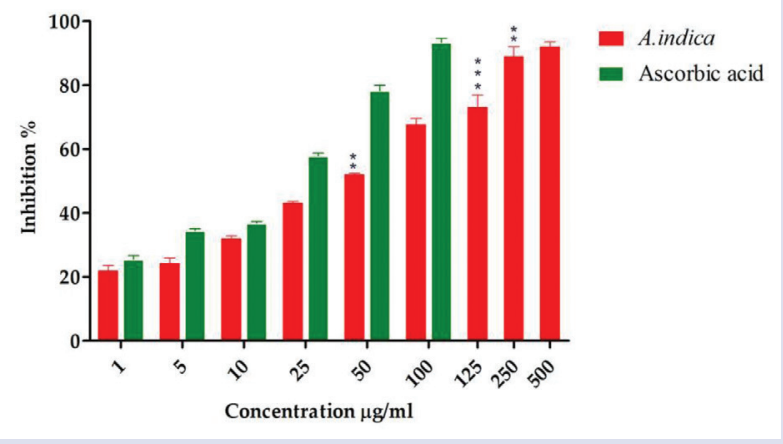

Figure 1: Antioxidant potential of A. bracteolata. 
a percentage inhibition of $16.65 \pm 0.64$, and for $100 \mu \mathrm{g} / \mathrm{ml}$, it showed $93.29 \pm 0.64$, respectively. Ascorbic acid was used as the reference drug. The range of ascorbic acid varied from 1 to $100 \mu \mathrm{g} / \mathrm{mL}$. Ascorbic acid at a concentration of $1 \mu \mathrm{g} / \mathrm{mL}$ exhibited a percentage inhibition of $24.80 \pm 0.98$

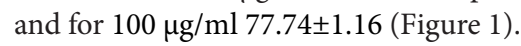

\section{HPTLC analysis}

\section{Quantification of quercetin from A. bracteolata extracts by HPTLC}

The Methanolic extracts of $A$. bracteolata leaves were prepared, and HPTLC quantified the amount of quercetin present in these extracts. As shown in Figure 2A, spots of quercetin seen at UV-254 nm in the TLC chromatogram. The bluish fluorescent spots of quercetin, however, were more easily detected at UV-365 nm in the chromatogram of both the extract. The data of peak areas were plotted against the corresponding concentrations as shown in Figure 2B. The amount of quercetin was found to be $1.28 \mathrm{w} / \mathrm{w}$ The identity of the quercetin bands in sample chromatograms was further confirmed by comparing retention factors of quercetin from the sample and standard solutions.

\section{Cytotoxicity effect on HDF and $\mathrm{HaCaT}$ cells}

The MTT assay determined the cytotoxicity effect of $A$. bracteolata on $\mathrm{HDF}$ and $\mathrm{HaCaT}$ cell lines. As shown in Figure $3 \mathrm{~A}$ and $3 \mathrm{~B}$ the plant extract significantly increased the number of cells in a dose-dependent manner. $\mathrm{IC}_{50}$ values were $87.60 \pm 1.67 \mu \mathrm{g} / \mathrm{mL}$ for $A$. bracteolata for HDF

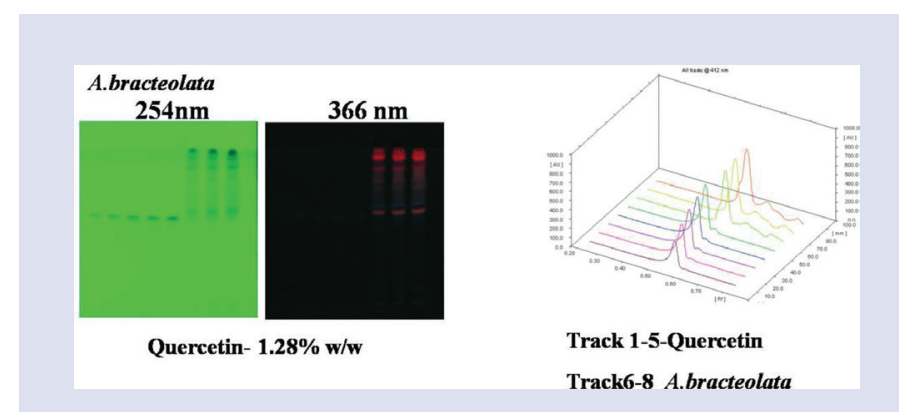

Figure 2: Quantification of quercetin from A. bracteolata extracts by HPTLC.

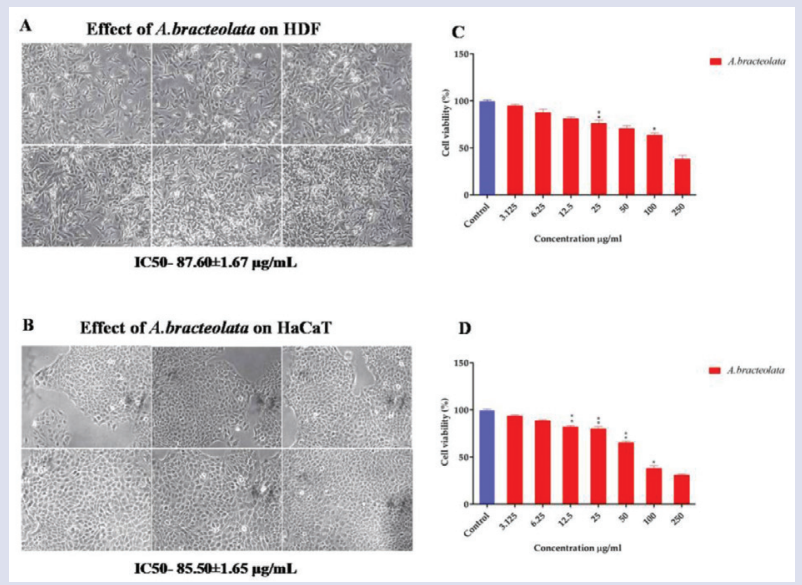

Figure 3 : Cytotoxicity effect of $A$. bracteolata on HDF and $\mathrm{HaCaT}$ cell lines. and $85.50 \pm 1.65 \mu \mathrm{g} / \mathrm{mL}$ for HaCaT after $24 \mathrm{~h}$ treatment analyzed by Graph Pad Prism 5.0 software, respectively. At low concentrations $(3.125 \mu \mathrm{g} / \mathrm{mL})$, the cell proliferation rates of $\mathrm{HDF}$ and $\mathrm{HaCaT}$ increased in a dosedependent manner and peaked at $88.03 \% \pm 1.78$ for $\mathrm{HDF}$ and $89.15 \%$ \pm 0.31 for $\mathrm{HaCaT}$ respectively (Figure $3 \mathrm{~A}$ and $3 \mathrm{~B}$ ). There was a significant increase in cell number when compared to the control $(\mathrm{p}<0.05)$. At higher concentrations $(250 \mu \mathrm{g} / \mathrm{mL})$, the plant extract was cytotoxic to cells, and the cell survival rates dropped to $20-40 \%$ in all cells (Figure 3C and 3D). The vehicle (DMSO) did not affect basal cell viability. Studies with different concentrations of DMSO (0.2-1.5\%) showed toxic effects at concentrations above $1 \%$, whereas lower concentrations $(<0.5 \%)$ of DMSO exhibited negligible effects. ${ }^{9}$ Therefore, only DMSO concentrations less than $0.5 \%$ were used in further experiments.

\section{Thymidine incorporation assay}

To confirm the ability of $A$. bracteolata to stimulate cell proliferation $3[\mathrm{H}]$ Thymidine incorporation assay was performed in both HDF and HaCaT cell lines. Thymidine is incorporated into newly synthesized DNA during the proliferative period of the cells. As shown in Figure 4, 2 fold increase in thymidine incorporation was observed with the treatment of A.bracteolata at a concentration of $25 \mu \mathrm{g} / \mathrm{mL}$ in HDF compared with the control $(\mathrm{p}>0.05)$ within $24 \mathrm{~h}$ of treatment. Similarly, in HaCaT cell lines, a 2.5 fold increase was observed in the $50 \mu \mathrm{g} / \mathrm{mL}$ of $A$. bracteolata compared with the control $(\mathrm{p}<0.05)$, (Figure 4$)$. The results indicate that significantly higher levels of thymidine incorporation were observed in cells treated with A. bracteolata in both HDF and HaCaT cell lines $(\mathrm{p}<0.05)$. Accordingly, based on the thymidine proliferation results in a dose of $25 \mu \mathrm{g} / \mathrm{mL}$ concentration of A. bracteolata for HDF and $50 \mu \mathrm{g} / \mathrm{mL}$ of extracts in $\mathrm{HaCaT}$ for treatment selected for all our further studies.

\section{Wound migration assay}

The effect of two plant extracts on proliferation and migration of HDF cells was tested in an in vitro (cell culture) wound healing model, in which scrape wounds were generated in confluent cell cultures. Cells with or without treatment of plant extracts were allowed to migrate into the denuded area for $24-48 \mathrm{~h}$ at $37^{\circ} \mathrm{C}$ and wound migration was determined by using image $\mathrm{J}$ software. We first investigated the effect of A. bracteolata on human dermal fibroblast cell migration and proliferation with a Standard in vitro model of wounding based on a scratch wound

\section{Thymidine incorporation assay:}

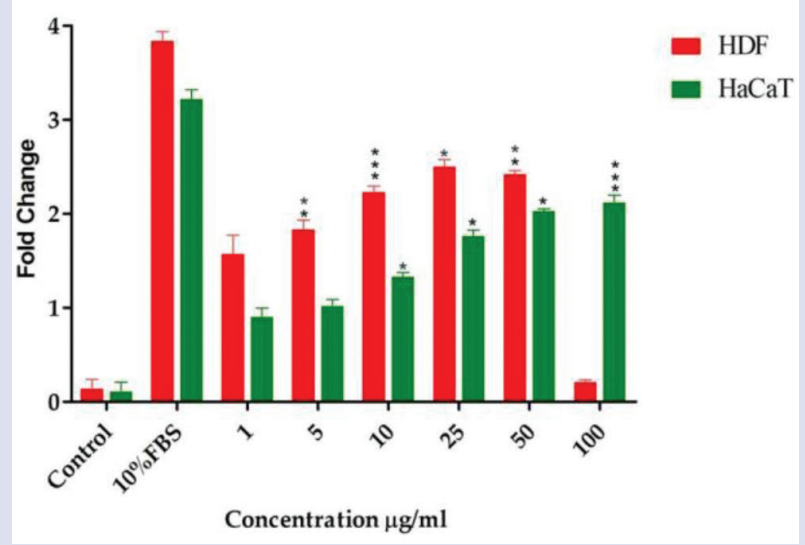

Figure 4: Thymidine incorporation assay. 


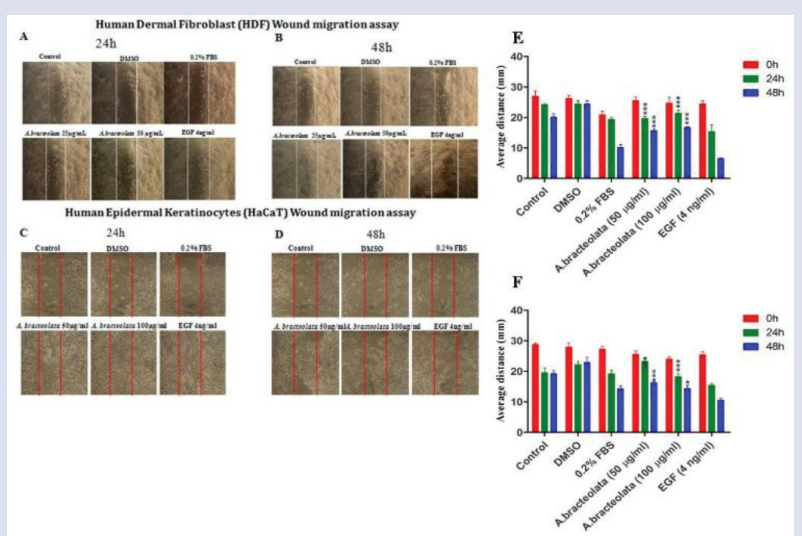

Figure 5 : In vitro Scratch Assay of A.bracteolata in $\mathrm{HDF}$ and $\mathrm{HaCaT}$ cells.

assay. The examined methanolic extract of $A$. bracteolata demonstrated a migration and proliferation activity with values of $50.38 \% \pm 1.39$ and $69.81 \% \pm 1.89$, respectively. Cells with $A$. bracteolata treatment were less mobile, as indicated by fewer cells in the denuded area at 24 and $48 \mathrm{~h}$ after scratching (Figure 5A-D) at a concentration of $25 \mu \mathrm{g} / \mathrm{mL}$, respectively $(\mathrm{p}<0.05)$.

\section{In vitro anti-inflammatory study}

\section{Effect of $A$. bracteolata on cytotoxicity and NO} production in RAW 264.7 cells

The cytotoxicity of plant extracts was evaluated using MTT assay, A. bracteolata was found not to affect RAW264.7 cell viability at concentrations of up to $100 \mu \mathrm{g} / \mathrm{mL}$. However, the cytotoxicity of A. bracteolata was evaluated at a high concentration of $250 \mu \mathrm{g} / \mathrm{mL}$ (Figure 6A). The viability of RAW264.7 was found to be more than $80 \%$ (Figure 6B) at a concentration between $3-25 \mu \mathrm{g} / \mathrm{mL}$, and there is no effect on vehicle level.

\section{NO production}

To investigate the effect of plant extracts on NO production, we measured the accumulation of nitrite, a stable oxidized product of NO, in culture media. NO production was examined in RAW 264.7 cells stimulated with LPS in the presence or absence of plant extracts for $24 \mathrm{~h}$. LPS $(200 \mathrm{ng} / \mathrm{mL})$ stimulated cells had significantly increased nitrite levels compared with control. This stimulation was inhibited by A. bracteolata treatment in a concentration-dependent manner (Figure 6C). A. bracteolata caused $67 \%(\mathrm{p}<0.05)$ inhibition of NO production at a concentration of $100 \mu \mathrm{g} / \mathrm{mL}$ that showed statistical significance with the baseline control (100\%).

\section{Anti-inflammatory activities of $A$. bracteolata on RT-PCR analysis}

iNOS, IL- $1 \beta$, and TNF- $\alpha$ are differentially expressed in response to various inflammatory stimuli such as lipopolysaccharide (LPS). The RT-PCR analysis was done to determine whether the inhibitory effects of $\mathrm{A}$. bracteolata on the proinflammatory mediators NO is related to the modulation of the expression of iNOS. ${ }^{15}$ In unstimulated RAW 264.7 cells which were exposed to LPS, iNOS was strongly expressed, and A. bracteolata significantly inhibited iNOS expression in a dose-dependent manner (Figure 6D). We further investigated the effect of plant extracts on LPS-induced TNF- $\alpha$ and IL- $1 \beta$ release by RT-PCR. The LPS-activated RAW 264.7 cells produced inflammatory cytokines at significantly

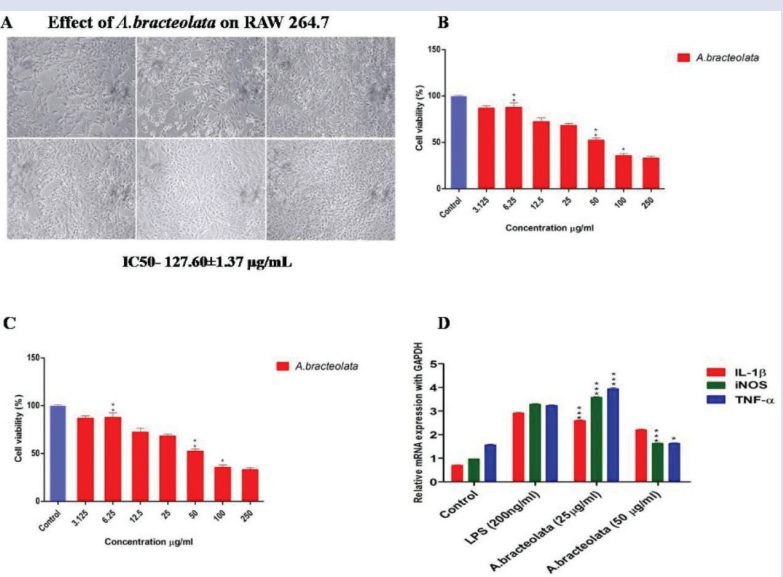

Figure 6: Cytotoxicity effect and RT-PCR analysis of $A$. bracteolata on RAW 264.7 cell lines.

\section{RT-PCR analysis}

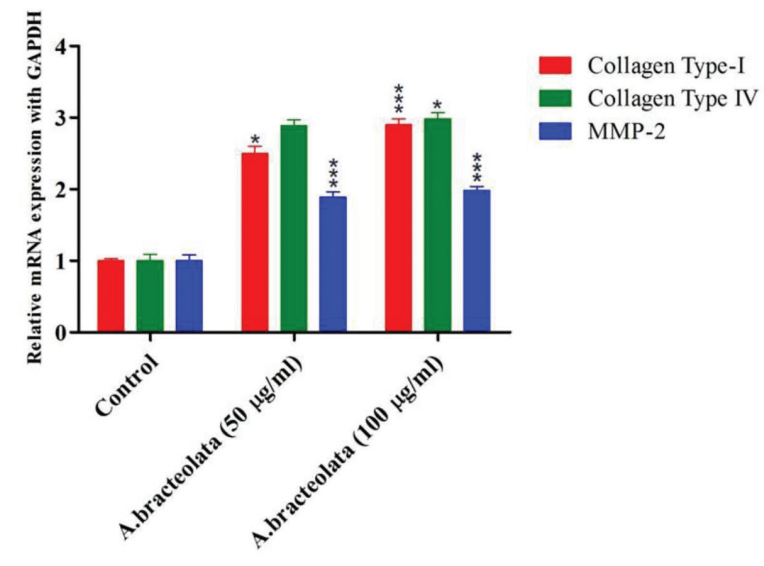

Figure 7: Real-Time PCR analysis of ECM.

higher levels than plant extracts $(\mathrm{p}<0.01)$. The TNF- $\alpha$ and IL- $1 \beta$ levels were augmented in the treatment of LPS-stimulated RAW 264.7 cells, and this increase in levels was significantly decreased in a concentrationdependent manner by treatment with A. bracteolata (Figure 6D).

\section{RT-PCR analysis}

Real-Time PCR analysis was performed to investigate the relative mRNA expression levels of selected remodeling enzymes, extracellular matrix components which are associated with wound repair, in HDF fibroblast culture. RT-PCR was performed on Type I and IV collagen and MMP-2. Figure 7 represents a significant upregulation of the extracellular matrix components such as Collagen Type I, Collagen Type IV in the treatment group compared with control $(p<0.05)$ while that of GAPDH remained unaffected. The mRNA levels of MMP-2 were further elucidated by realtime PCR after HDF cells were treated with A.bracteolata, As shown in Figure 7, MMP2 showing a significantly higher expression in dermal fibroblasts compared with control $(P<0.01)$. These data suggest that $A$. 


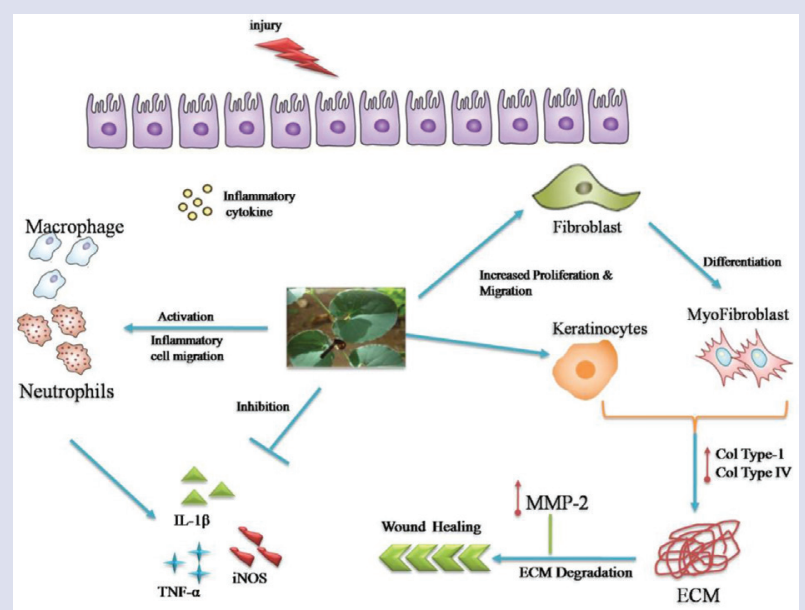

Figure 8: Schematic Representation of A.bracteolata on wound healing mechanism.

bracteolata in fibroblasts can directly induce the expression of ECM components (Figure 8).

\section{DISCUSSION}

There is a new interest in finding herbal extracts with wound healing efficacy even though the use of such natural extracts for treating cuts and wounds is a familiar practice in traditional medicine. The better wound healing potency of various herbal extracts may be attributed to the presence of phytochemicals and free radical-scavenging and the antimicrobial property of the constituents present in the natural extract, and the process of wound healing could be a function of either the individual or the synergistic effects of bioactive molecules. Our relevant findings were that the methanolic extract of $A$. bracteolata stimulated the migration of fibroblasts and keratinocyte cells in in vitro wound healing assay and enhanced the expression levels of genes that positively contribute to wound healing.

The extract of $A$. bracteolata was studied for in vitro antioxidant activity using DPPH assay. Both the plant extracts showed significant antioxidant activity compared with the standard ascorbic acid $(\mathrm{p}<0.05)$. Similar findings were observed from. ${ }^{16,17}$ Some recent studies showed that ethanol extract of $A$. bracteolata had wound healing, anti-inflammatory, and antioxidant properties. ${ }^{7}$ Our study has also demonstrated that A. bracteolata possess significant antioxidative property. HPTLC analysis revealed the presence of Quercetin in the plant extract. The calibration plot shown in Figure $2 \mathrm{~A} \& \mathrm{~B}$ indicates that the response is a linear function of concentration in the range 200 to $1000 \mathrm{ng}$ Quercetin with the correlation coefficient of 0.98456 .

The cytotoxic effects of $A$. bracteolata on HDF and HaCaT cells were assessed using MTT assay. A dose-dependent increase in cell viability was observed during the $24 \mathrm{~h}$ treatment period with maximum and significant $(\mathrm{p}<0.05)$ increase at $25 \mu \mathrm{g} / \mathrm{mL}$ concentration level. High concentration of $A$. bracteolata $(250 \mu \mathrm{g} / \mathrm{mL})$ inhibited cell proliferation and displayed cytotoxic effect on $\mathrm{HDF}$ and $\mathrm{HaCaT}$ cells, respectively (Figure 3).

The main cell architect contributing in the process of wound healing by contraction is the keratinocytes and fibroblasts, which is involved in the synthesis and deposition of the extracellular matrix. Hence, the fibroblasts in vitro model are integral to correlating the contractile events of wound healing. ${ }^{18}$ Hence, the human dermal fibroblasts (HDF), growth- stimulating activity of plant compounds, is an appropriate technique to resolve the wound healing properties of the test compounds. ${ }^{19}$ The scratch assay covers the second phase of wound healing process which is characterized by migration of either keratinocytes or fibroblasts. ${ }^{20}$ Any growth factor that stimulates cell migration may help to generate an optimized therapeutic protocol for improved wound healing because cell migration is a crucial event in cutaneous wound healing. ${ }^{21}$ Consequently, as an in vitro analysis of skin cell behavior, scratch wound assay using HDF were performed. Results showed that A. bracteolata increased the rate of fibroblast wound closure compared with control at $48 \mathrm{~h}$. Our findings demonstrated that the scratch assay is a convenient and inexpensive method that gives robust and reproducible results for the proliferation with the induction of plant extracts as well as the migration of fibroblasts and keratinocytes in an artificial wounded area (Figure 5). Although the scratch assay cannot substitute in vivo studies as a final proof for efficacy in wound healing, this study confirms its usefulness for gaining first insight into the potential of an extract or compound to repair injured dermis. The better wound healing may, thus, be due to the free-radical scavenging effect of the plant, and the enhanced level of antioxidant enzymes in the tissues. ${ }^{7}$

For in vitro anti-inflammation study, the LPS induced RAW264.7 macrophage cells are widely used as a screening platform for anti-NO production activities. ${ }^{22}$ Bacterial infection or immunological stimuli LPS result in the production of a significant amount of NO by macrophages. High quantities of $\mathrm{NO}$ are potentially cytotoxic and capable of destructing the surrounding cells and tissues. ${ }^{23}$ iNOS, IL- $1 \beta$, and TNF- $\alpha$ are known to be the primary inflammatory mediators in the inflammatory stage of wound healing. Our results indicate that A. bracteolata is an effective inhibitor of LPS-induced NO, IL- $1 \beta$ and iNOS production in RAW264.7 macrophages. To further investigate the mechanism underlying this inhibition by the plant extracts, the expression levels of iNOS, IL- $1 \beta$, and TNF- $\alpha$, mRNA levels were examined by RT-PCR. The results demonstrated that the inhibitory effects of $A$. bracteolata were accompanied by a decrease in the expression of pro-inflammatory cytokine mRNA in a concentration-dependent manner (Figure 6).

Tissue remodeling involves various extracellular proteinases, particularly those belonging to the serine proteinase and MMP families. Extracellular proteases achieve the proteolytic degradation of ECM involving the MMPs. Among MMP, MMP-2 (gelatinase A) and MMP-9 (gelatinase B) contain an additional fibronectin-like domain close to the zinc-binding site. This domain increases the proteolytic activities of these two enzymes by mediating their binding to gelatin and collagen in the extracellular matrix. ${ }^{24}$ which represents the removal of the fibronectin-like type II repeats defined by exons 5-7, were compared with those of full-length gelatinase A. Both enzymes underwent self-activation over a similar time course in the presence of 4-aminophenylmercuric acetate. The fully active enzymes had similar kcat $/ \mathrm{Km}$ values for the cleavage of an octapeptide substrate, but the deletion mutant had $50 \%$ of the activity of wild type gelatinase A against beta-casein and $10 \%$ of the activity against gelatin. The cleavage pattern for gelatin was similar for both enzymes but differed for type IV collagen. Comparison of the rates of association of the tissue inhibitors of metalloproteinase (TIMP).

During dermal wound healing, various types of MMPs are expressed in a coordinated fashion. MMP-2 is mainly expressed by fibroblasts. ${ }^{25}$ All the MMPs are synthesized and released as zymogens called pro-MMP and need to be activated by proteolytic cleavage. In this study, we studied the expression and activation of MMP 2 using in vitro scratch wound model in human dermal fibroblast cell lines. Our results showed that there is an elevated expression of MMP-2 in RT-PCR analysis. The increased expression may be due to the proliferation and accumulation of HDF cells by plant extracts at the wound bed which activates MMP-2 
which acts locally to degrade collagen molecules generated either during the late phase of inflammation or the first steps of extracellular matrix remodeling. It has been shown that MMP-2 plays an important role during granulation and early phases of the wound-healing process and localizes mainly in fibroblasts and endothelial cells. ${ }^{26}$ Moreover, recent data showed that MMP-2 might be the enzyme first and foremost responsible for collagen degradation in tissues where a high extracellular matrix turnover is observed. ${ }^{25}$ On the other hand, by its capability to degrade type IV collagen, MMP-2 could also participate in the basement membrane remodeling which occurs during angiogenesis. Taken together, our results demonstrate that MMP 2 is selectively expressed or activated at the successive periods of wound healing. An adequate combination of different MMPs is required for wound remodeling. The prolonged expression of MMP-2 induced by plant extracts in HDF cells might facilitate essential events of wound healing such as cell migration, neoangiogenesis, and tissue remodeling, and overall accelerate the repair process.

A fibroblast is the connective tissue cell responsible for collagen deposition that is needed to repair the tissue injury. In normal tissues, collagen provides integrity, strength, and structure. When tissues are disrupted following injury, collagen is necessary to fix the defect and restore anatomic structure and function. ${ }^{27}$ but overlapping phases: hemostasis, inflammation, proliferation and remodeling. Specific biological markers characterize healing of acute wounds. Likewise, unique biologic markers also characterize pathologic responses resulting in fibrosis and chronic non-healing ulcers. This review describes the major biological processes associated with both normal and pathologic healing. The normal healing response begins the moment the tissue is injured. As the blood components spill into the site of injury, the platelets come into contact with exposed collagen and other elements of the extracellular matrix. This contact triggers the platelets to release clotting factors as well as essential growth factors and cytokines such as platelet-derived growth factor (PDGF An enhance in collagen production is a major factor in wound healing. Type-I collagen is the main collagen of bone, skin, tendon, and newly healed wounds. ${ }^{28}$ The ethanolic extracts of $A$. bracteolata at two different dose levels of 400 and $800 \mathrm{mg} / \mathrm{kg} /$ body showed a definite, positive effect on wound healing. With a significant increase in the level of two powerful antioxidant enzymes, superoxide dismutase, and catalase, in the granuloma tissue [Shirwaikar et al., 2003]. Semi-quantitative RT-PCR analysis showed abundance in the expression of the type I and type III collagen transcripts in the treatment group compared with the control groups. The results demonstrated that collagen type I and type $\mathrm{IV}^{29}$ production in HDF cells increased significantly after treatment with A. bracteolata at concentrations 25 and $50 \mu \mathrm{g} / \mathrm{mL}(\mathrm{p}<0.01)$ as compared to the control (Figure 7). The levels of type III collagen are also known to get increased during early stages of healing. ${ }^{29}$ During the initial stage of wound healing, type IV collagen is synthesized which will be replaced by type I collagen during a later stage of wound repair. It is evident from the data that the plant extracts could stimulate collagen production from fibroblast cells resulting in increasing levels of ECM during tissue repair (Figure 8). The expression and secretion of type I and type IV collagens are also inherent to the biological functions of fibroblasts because these proteins are essential components of the extracellular matrix.

\section{CONCLUSION}

The results obtained in the present study indicate that the A. bracteolata extract possesses significant wound healing activity in in vitro model. The wound healing effect of this plant extract may be due to synergistic active principles. A. bracteolata has anti-inflammatory, anti-oxidative, anti-bacterial, and stimulatory effects on fibroblast proliferation and thus can be considered as an appropriate stimulus for healing. Appli- cability and clinical use of this medicinal plant require more accurate and complete studies, determination of type and percentage of active compounds in the extract, and pharmacological trials. Based on these results further studies can be carried out aiming at elucidation of the molecular process and signaling pathways underlying proliferation and migration of the fibroblasts and keratinocytes induced by plant extracts. Further pharmacological and biochemical investigation has to be undertaken to elucidate the mechanism of action clearly and would be helpful in projecting this plant as a therapeutic target in wound healing and other diseases. Thus, the present research scientifically validates the use of A.bracteolata in wound healing.

This study highlights the potential of the plant extract as an anti-inflammatory and wound healing agent. The present study provides scientific evidence that the extract of A. bracteolata has potential wound healing activity due to a combination of fibroblast stimulation and inhibition of inflammatory phase of wound healing as demonstrated by reduced levels of inflammatory cytokines from macrophage Raw 264.7 cells by increasing collagen type I and 4 .

\section{ACKNOWLEDGEMENT}

The work was supported by a grant from Department of Biotechnology, Government of India (BT/Bio-CARe/07/10221/2013-14).

\section{CONFLICT OF INTEREST}

The authors declare no conflict of interest with regard to this publication.

\section{ABBREVIATION USED}

ECM: Extracellular matrix; EGF: Epidermal growth factor; HaCaT: Human keratinocyte cell line; HDF: Human dermal fibroblast; HPTLC: High-performance thin layer liquid chromatography; iNOS: inducible nitric oxide synthase; LPS: Lipopolysaccharide; MMP-2: Matrix metalloproteinase-2; NO: Nitric oxide; PCR: Polymerase chain reaction; PDGF: Platelet derived growth factor; TIMP: Tissue inhibitors of metalloproteinase; TNF- $\boldsymbol{\alpha}$ : Tumor necrosis factor- $\alpha$.

\section{REFERENCES}

1. Ansari MM. Therapeutic Potential of Canine Bone Marrow Derived Mesenchymal Stem Cells and its Conditioned Media in Diabetic Rat Wound Healing. J Stem Cell Res Ther. 2013;3(141):2

2. Radhakrishnan N, Majumder S, Chatterjee S, Gnanamani A. Evaluation of wound healing and chemotactic activities of Embelin and Vilangin using human dermal fibroblast (in vitro) model. J Chem Pharm Res. 2013;5:768-73.

3. Schmidt C. Biological studies on Brazilian plants used in wound healing. J Ethnopharmacol. 2009;122(3):523-32.

4. Sasidharan S, Nilawatyi R, Xavier R, Latha LY, Amala R. Wound healing potential of Elaeis guineensis Jacq leaves in an infected albino rat model. Molecules. 2010;15(5):3186-99.

5. Thirumal M, Vadivelan R, Kishore GBV. Aristolochia bracteolata: An Overview on Pharmacognostical, Phytochemical and Pharmacological Properties. 2009;3(1):70-82.

6. Chitme HR, Patel NP. Antiarthritis Activity of Aristolochia Bracteata Extract in Experimental Animals. The Open Natural Products Journal. 2009;2:6-15.

7. Shirwaikar, Somashekar P, Udupa L, Udupa SL, Somashekar S. Wound healing studies of Aristolochia bracteolata Lam. with supportive action of antioxidant enzymes. Phytomedicine. 2003;10(6):558-62.

8. Ranzato E, Martinott S, Burlando B. Honey exposure stimulates wound repair of human dermal fibroblasts. Burns \& Trauma. 2013;1(1):32-8

9. Fronza M, Heinzmann B, Hamburger M, Laufer S, Merfor I. Determination of the wound healing effect of Calendula extracts using the scratch assay with 3T3 fibroblasts. Journal of Ethno Pharmacology. 2009;126(3):463-67.

10. Kashyap AK, Reddy NP, Chaitanya RK, Karnati R. Ethyl acetate extract of Hemigraphis colorata leaves shows anti-inflammatory and wound healing properties and inhibits 5-lipoxygenase and cyclooxygenase-1 and 2 enzymes. Journal of Medicinal Plant Research. 2013;7(37):2783-91.

11. Mosmann T. Rapid colorimetric assay for cellular growth and survival: Application to proliferation and cytotoxicity assays. J Immunol Methods. 1983;65(1-2):55-63.

12. Liang CC, Park AY, Guan JL. In vitro scratch assay: a convenient and inexpensive 
method for analysis of cell migration in vitro. Nat. Protoc. 2007;2(2):329-33.

13. Tang J. A small peptide with potential ability to promote wound healing. PLoS One. 2014;9(3).

14. Akram KM, Samad S, Spiteri M, Forsyth NR. Mesenchymal stem cells promote alveolar epithelial cell wound repair in vitro through distinct migratory and paracrine mechanisms. Respir Res. 2014;14(1):9.

15. Kang OH, Chae HS, Choi JG, Oh YC, Lee YS, Kim JH, et al. ent-pimara-8 (14), 15-dien-19-oic acid isolated from the roots of Aralia cordata inhibits induction of inflammatory mediators by blocking NF-кB activation and mitogen-activated protein kinase pathways. European journal of pharmacology. 2008;601(1):179-85.

16. Nahrstedt A, Hungeling M, Petereit F. Flavonoids from Acalypha indica. Fitoterapia. 2006;77(6):484-86.

17. Balakrishnan N, Panda AB, Raj NR. The Evaluation of Nitric Oxide Scavenging Activity of Acalypha indica Linn root. Asian J Res Chem. 2009;2(2):148-50.

18. Margaret I, Srinivasa RP, Kaiser J. Anti-inflammatory profile of Tridax procumbens in animal and fibroblast cell models. Phyther Res. 1998;12(4):285-87.

19. Stevenson PC, Simmonds MSJ, Sampson J, Houghton PJ, Grice P. Wound healing activity of acylated iridoid glycosides from Scrophularia nodosa. Phyther Res. 2002;16(1):33-5

20. Schäfer M, Werner S. Transcriptional Control of Wound Repair. Annu Rev Cell Dev Biol. 2007;23:69-92.

21. Kim SW, Zhang HZ, GuoL, Kim JM, Kim MH. Amniotic mesenchymal stem cells enhance wound healing in diabetic NOD/SCID mice through high angiogenic and engraftment capabilities. PLoS One. 2012;7(7):e41105

22. Tam JC. et al. The in vivo and in vitro diabetic wound healing effects of a 2-herb formula and its mechanisms of action. J EthnopharmacoL. 2011;134(3):831-8.

23. Laskin DL, Sunil VR, Gardner CR, Laskin JD. Macrophages and Tissue Injury: Agents of Defense or Destruction?. Annu Rev Pharmacol Toxicol. 2011;51:267-88.

24. Murphy G. Assessment of the role of the fibronectin-like domain of gelatinase A by analysis of a deletion mutant. J Biol Chem. 1994;269(9):6632-36.

25. Siméon A, Wegrowski Y, Bontemps $Y$, Maquart FX. Expression of glycosaminoglycans and small proteoglycans in wounds: Modulation by the tripeptide-copper complex glycyl-L-histidyl-L-lysine-Cu2+. J Invest Dermatol. 2000;115(6):96268.

26. Garcı M, Carretero M, Retamosa L, Jorcano JL, RM. In vitro and In vivo Wound Healing-Promoting Activities of Human Cathelicidin LL-37. Journal of Investigative Dermatology. 2007;128(1):223-36

27. Diegelmann RF. Wound healing: an overview of acute, fibrotic and delayed healing Front Biosci. 2004;9(1):283-9.

28. Aramwit $P$, Kanokpanont $S$, Nakpheng T, Srichana T. The effect of sericin from various extraction methods on cell viability and collagen production. Int $\mathrm{J} \mathrm{Mol}$ Sci. 2010;11(5):2200-11.

29. Barnes MJ, Morton LF, Bennett R, Bailey AJ, Sims TJ. Presence of type III collagen in guinea-pig dermal scar. Biochem J. 1976;157(1):263-65.

\section{GRAPHICAL ABSTRACT}

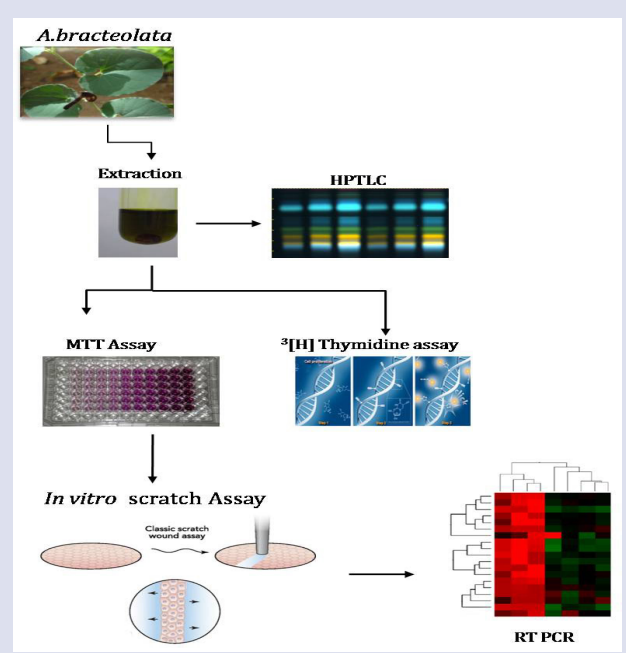

\section{SUMMARY}

- Antioxidant assay of the methanolic extract of $A$. bracteolata exhibited a comparable antioxidant activity with that of standard ascorbic acid.

- Cytotoxic effect of plant extracts by MTT and cell proliferation analysis by thymidine incorporation assay demonstrated significant effect of plant extracts on HDF and HaCaT cell lines.

- Scratch wound assay revealed the effect of plant extracts on fibroblasts and keratinocytes migration by restoring the cells to the confluent state at $48 \mathrm{~h}$ The mRNA expression of wound healing associated gene was carried out and significant results was obtained.

\section{ABOUT AUTHORS}

Dinesh Murugan Girija: Pursuing Ph.D in Centre for Indian Systems of Medicine Quality Assurance and Standardization. Sri Ramachandra University, Chennai, India. His area of expertise and interest includes evaluation of traditional herbal medicine, research and development of new biologically active substances in stem cells therapeutic developments.

Mangathayaru Kalachaveedu: Professor, Department of Pharmacognosy, Faculty of pharmacy. Sri Ramachandra University, Chennai, India. Her area of expertise and interest includes phytopharmacological validation of traditional medicine with specific focus on anti atherosclerotic, anti diabetic and anti cancer and wound healing potential of classical/folklore herbs. Author of a 470 page text book on Pharmacognosy, her current focus is in clinical pharmacognosy for herb-drug interactions of turmeric in oncology.

Rajasekaran Subbarayan: Pursuing Ph.D in Centre for Regenerative Medicine and Stem Cell Research, Sri Ramachandra University, Chennai, India. His area of expertise and interest includes developing stem cells based treatments for spinal cord injury.

Preethi S Jenifer: Presently working as Junior Research Fellow in DBT project and pursuing Ph.D in Faculty of Pharmacy, Sri Ramachandra University, Chennai, India. Her area of expertise and interest are developing nano based wound dressing materials from traditional medicinal plants for therapeutic application.

Suresh Rao: Professor of Periodontology and implantologist, Sri Ramachandra Dental College, Sri Ramachandra University. Research interest :inflammation, stem cell and tissue engineering . 25 years of teaching experience . Winner of first ever Europerio virtual presentation, Vienna, Austria.

Cite this article: Girija DM, Kalachaveedu M, Subbarayan R, Jenifer P, Rao SR. Aristolochia bracteolata Enhances Wound Healing in vitro through Anti-inflammatory and Proliferative Effect on Human Dermal Fibroblasts and Keratinocytes. Pharmacog J. 2017;9(6) Suppl:s129-s36. 